\title{
Application of a Depression Management Office System in Community Practice: A Demonstration
}

\author{
Allen J. Dietrich, MD, Thomas E. Oxman, MD, Mary R. Burns, MS, \\ Charlotte W. Winchell, MSW, and Tanya Chin, MD
}

Background: Recent studies provide new insights about strategies that improve depression outcomes. We explored the feasibility of implementing these strategies in community practices.

Methods: Clinicians followed an office system approach to management of depression. There were no controls. The office system was based on established routines performed by a primary care clinician working in a prepared practice, a telephone care manager, and a collaborating psychiatrist, all using a common severity monitoring tool.

Five practices with 18 clinicians participated. Sixty-six adult patients had depression diagnosed, and 60 (91\%) received care according to the model through 8 weeks of follow-up visits. Depression outcomes were assessed using PHQ-9.

Results: At baseline, $48(80 \%)$ patients met criteria for major depressive disorder, chronic depression, or both, while others had less severe symptoms. Of 32 patients with moderately severe or severe depression, the 8 -week follow-up severity score decreased by $\geq 50 \%$ for $23(70 \%)$. of patient barriers to adherence, ambivalence about treatment and medication side effects were most common. Most patients received three care manager telephone calls requiring 6 to 10 minutes each.

Conclusion: Application of the office system was feasible in this demonstration project. If results are confirmed in further studies, this approach will be appropriate for widespread application. ( $\mathrm{J}$ Am Board Fam Pract 2003;16:107-14.)

Most patients who suffer from depression are seen in primary care. ${ }^{1,2}$ Barriers to successful treatment include patient ambivalence, the confidence and skills of the patient's primary care provider, and costs, among many other things. ${ }^{3,4}$

Recent controlled trials have found some useful strategies that improve outcomes for patients suffering from depression. Katon et $\mathrm{a}^{5,6}$ have shown the benefits of formal collaboration between family physicians and mental health specialists. Others have shown improved patient outcomes with telephone support provided by trained staff. ${ }^{7-9}$ Wells et $\mathrm{al}^{10}$ and Rost et $\mathrm{al}^{11}$ found increased remission rates with formally structured approaches to care that include defined intervals of follow-up, cooperation among members of a care team, and modifi-

Submitted 1 May 2002.

From the Departments of Community and Family Medicine (AJD, MRB, CWW, TC) and Psychiatry (TEO), Dartmouth Medicine School, Hanover, NH. Address correspondence to Allen J. Dietrich, MD, Department of Community and Family Medicine, 7250 Strasenburgh Hall, Dartmouth Medical School, Hanover, NH 03755.

Presented in part at North American Primary Care Research Group Annual Meeting, Halifax, Nova Scotia October $13-15,2001$. This work was supported by the John D. and Catherine T. MacArthur Foundation. cation of the treatment approach if patient response is not adequate.

Other developments are notable as well. A selfadministered instrument derived from PRIME$\mathrm{MD},{ }^{12}$ the PHQ-9, ${ }^{13}$ provides a new practical tool for assessing depression diagnosis and severity. Wagner and colleagues ${ }^{14}$ have advocated application of the planned care model in the management of chronic diseases including depression. Von Korff and Goldberg ${ }^{15}$ have described low-cost case management and better communication between primary care and mental health specialists as key elements to improve depression management. The PHQ-9 can provide a valuable tool to support application of these evidence-based strategies, including planned care and better communication among clinicians.

An office system has been defined as established routines, a division of responsibilities among clinical personnel, and appropriate tools to accomplish a task. ${ }^{16}$ Office systems have been shown to improve performance of preventive services in earlier research. ${ }^{17,18}$ We developed an office systems approach to the primary care management of depression and explored feasibility and impact of imple- 
Table 1. The Three-Component Model: A Depression Management Office System.

\begin{tabular}{llll}
\hline Component & \multicolumn{1}{c}{ Responsibilities } & Routines & \multicolumn{1}{c}{ Tools } \\
\hline $\begin{array}{l}\text { Primary care clinician in a } \\
\text { prepared practice }\end{array}$ & $\begin{array}{l}\text { Recognition } \\
\text { Management }\end{array}$ & $\begin{array}{l}\text { Diagnostic assessment } \\
\text { Follow-up visits* }\end{array}$ & $\begin{array}{l}\text { PHQ-9 } \\
\text { Patient education materials } \\
\text { Communication forms }\end{array}$ \\
Care manager & Promote adherence & Periodic telephone calls ${ }^{\dagger}$ & $\begin{array}{l}\text { PHQ-9 } \\
\text { Patient education materials } \\
\text { Conitor response }\end{array}$ \\
& & & Communication forms \\
Collaborating psychiatrist & Support care manager and & Weekly supervisory calls & Communication forms \\
& primary care clinician & Informal advice & Comm \\
\hline
\end{tabular}

*Typical intervals for follow-up office visits were 2, 6, and 12 weeks.

${ }^{\dagger}$ Care managers called at $1,4,8$ weeks, and as needed.

mentation in a demonstration project. This article reports the results.

\section{Methods \\ Setting}

The six community primary care practices nearest to Dartmouth Medical School were approached to participate. Five practices agreed and one 2-person practice declined to participate. The protocol was reviewed and approved by the Institutional Review Board.

\section{Study Design and Patients}

Each clinician agreed to select a consecutive series of up to 5 adult patients suffering from depression. There were no control patients. Patients had to be sufficiently distressed, in their clinicians' clinical opinion, to require active treatment with medication, psychological counseling, or both. Exclusions included patients less than 18 years of age, those who were pregnant, patients without a telephone, those who were demented, or those who in the view of their clinician had a life expectancy of less than 1 -year. To reflect actual practice, all referred consenting patients were accepted into the program. Patients were not required to meet formal diagnostic or severity criteria for depressive disorders.

\section{The Depression Management Office System}

With help from project staff, clinicians established a depression management office system in their practices, subsequently referred to as the threecomponent model of depression care. The components refer to three corresponding professional roles: the primary care provider working in a prepared practice, a telephone care manager, and a supportive psychiatrist. Each of these office system components is described below. The relation between components and responsibilities, routines, and tools is summarized in Table 1.

All three professional roles collaborate as partners following specific routines based on Agency for Health Care Policy and Research (AHCPR) recommendations. ${ }^{1,2}$ These routines include a structured diagnostic assessment and close followup monitoring of patient response at intervals, modifying the management approach as necessary. These AHCPR recommendations were updated to reflect recent research that has shown the value of telephone support for patients from trained staff, ${ }^{19}$ an improved interface between primary care and mental health providers, ${ }^{6,7}$ and the value of the PHQ-9 to assess diagnosis, symptom severity, and treatment response. ${ }^{13}$

Besides responsibilities and routines, tools are important as well in office systems. The one central tool for the depression management office system addresses depression severity and diagnosis and facilitates communication among primary care clinicians, care managers, and the collaborating psychiatrist. The PHQ-9 is the depression section of a patient self-administered instrument derived from the PRIME-MD ${ }^{12}$ and DSM-IV. ${ }^{20}$ It lists nine potential symptoms of depression and asks that patients rate the frequency of experiencing each symptom during the past 2 weeks $(0=$ never, $1=$ sometimes, 2 = greater than one half the time, and 3 = almost always), yielding a score of 0 to 27 . Recent validity research indicates that scores of 5 , 10, 15, and 20 represent mild, moderate, moderately severe, and severe depression, respectively. ${ }^{13}$

A drop of 5 or more points from baseline after 4 weeks is considered a sign of initial treatment response. A 50\% response is considered adequate at 8 
weeks. A total score of less than 5 on the PHQ-9 is considered remission. We also used a question asking the degree to which symptoms limited function. One additional question was added to inquire whether the symptoms had been present for 2 years or longer, suggesting chronic depression. Other potential office system tools include patient educational materials and standard forms to facilitate communication and recording.

Having described the office system routines and tools, responsibilities require further amplification, including how the tools and routines are incorporated with them. The primary care clinician working in a prepared practice refers to practices that have received education for both the clinicians and office staff about updated AHCPR guidelines and routines, skills needed for use of PHQ-9, and use of communication forms. A 2-hour clinician education session and a 30-minute office staff in-service provided the necessary forums for this education and introduced the care manager and the psychiatrist to the practice.

Care management consists of a series of telephone calls at 1, 4, and 8 weeks after patient enrollment, as well as additional follow-up telephone calls, as needed, to answer patient questions, promote adherence to the clinician's management plan, and to help patients overcome any barriers to adherence. For example, if the patient did not fill a prescription for an antidepressant by the 1-week call, the care manager addressed barriers and then called again in a few days to confirm that the prescription had been filled. The care manager role was structured to fit the skills of a practice-based medical assistant or centrally based staff person with telephone triage experience but not to require diagnostic or management decisions or psychological counseling skills. For this demonstration project, a social worker based at a central location filled the role of care manager.

At 4 and 8 weeks the call also included readministration of the PHQ-9. A report on each telephone call (including depression severity scores) was sent immediately by fax to the clinician's office. The timing of these reports assured that information to make clinical decisions was available to the clinician at each follow-up appointment. If the patient on any of these telephone calls indicated thoughts of death or of suicide risk, a formal suicide risk protocol was followed.
Enhanced mental health support through a collaborating psychiatrist is informed by earlier research. ${ }^{15}$ Enrolled patients and their progress were discussed weekly by telephone between the care manager and the psychiatrist to provide specialty input and support. In some cases based on these telephone calls, the psychiatrist proactively called the primary care clinician to offer management suggestions, especially if the patient showed an inadequate response to treatment at 4 or 8 weeks, based on the severity assessment. The psychiatrist was available by pager to the clinicians and at several designated hours per week to answer queries about diagnosis or management.

\section{Implementing the Depression Management office System}

The office system was implemented with external support from project staff consistent with what could be provided through the quality improvement infrastructure of a medical group. Clinicians were provided with education in a credit-bearing continuing medical education format that emphasized interaction. The office staff in-services were led by an experienced office manager and took place during routine staff meetings. ${ }^{*}$

For this demonstration, care management was provided centrally to assure consistent application of the role. Care management was provided in a format consistent with chronic illness care management that is already provided by some payers and practices for diabetes, congestive heart failure, and other chronic conditions. ${ }^{21}$ Practice-based medical assistants or nurses could provide these functions as well.†

In this demonstration, a well-respected local psychiatrist filled the supervising psychiatrist role. An alternative approach to filling this role would be through a co-located mental health provider or through a primary care clinician in the practice who has a high degree of clinical competence in depression.

*Presentation materials are available from the corresponding author. An alternative source of clinician information for use in self-instruction is the MacArthur Foundation Initiative on Depression and Primary Care Tool Kit, which is available on the Internet at http: www.depressionprimarycare.org.

†Training materials for care managers are available from the corresponding author. 


\section{Evaluation}

In addition to demographics, the severity of depression was classified at baseline according to depression diagnosis using PHQ-9. The diagnosis of major depressive disorder followed DSM-IV criteria: those indicating that they had suffered at least half the time during the past 2 weeks from five or more of the nine symptoms listed by DSM-IV, including depressed mood, anhedonia, or both, were classified as suffering from major depressive disorder. Patients who also indicated that they had suffered from depressive symptoms for at least 2 years were considered to have both major depressive disorder and chronic depression. Patients who suffered from depressive symptoms for at least 2 years but who did not meet full criteria for major depressive disorder were classified as having chronic depression.

Evaluation addressed establishing the office system, the process of care for enrolled patients, patient outcomes after 8 weeks, and resources needed to implement and maintain the three-component model, specifically personnel time. The care manager maintained contact lists that recorded each attempted call and the content and timing of all telephone calls completed. The PHQ-9 provided the basis of outcome assessment and was administered initially by the clinicians and readministered by the care manager as part of telephone calls at 4 and 8 weeks. Data are summarized as means or percentages, as appropriate.

\section{Results}

The five participating practices included 18 clinicians, 12 family physicians, and 6 midlevel practitioners. Men and women were equally represented. The mean time in practice was 10.5 years with a range of 1 to 24 years. All participated in the clinician education session, and practice staff cooperated fully with office in-services provided at each practice.

Sixty-six patients were referred during a 2-month period, and 60 (91\%) completed the 8 -week follow-up telephone call. Three of the 66 failed to complete the first care management telephone call, and 3 additional patients were lost to follow-up before completing the 8-week follow-up telephone call. Characteristics of patients are summarized in Table 2. The most common diagnosis was major depressive disorder with chronic depression. Almost one half indicated that their symptoms
Table 2. Baseline Characteristics of Patients $(n=60)$.

\begin{tabular}{lc}
\hline Characteristic & Value \\
\hline Age, years & \\
Mean & 47 \\
Range & $18-88$ \\
& No. (\%) \\
Female & $43(72)$ \\
Initial diagnosis & \\
MDD & $15(25)$ \\
CD & $11(18)$ \\
Both MDD and CD & $22(37)$ \\
Other & $12(20)$ \\
Does condition limit your function? & \\
Extremely & $6(10)$ \\
Very much & $21(35)$ \\
Somewhat & $31(52)$ \\
Not at all & $2(3)$ \\
Initial management & \\
Medication only & $33(55)$ \\
Psychological counseling only & $4(7)$ \\
Both & $23(38)$ \\
\hline
\end{tabular}

Note: MDD = major depressive disorder, $\mathrm{CD}=$ chronic depression. Other includes those with fewer or less severe depressive symptoms.

limited their function extremely or very much. Medication was prescribed for 56 of the 60 patients $(93 \%)$ as their initial treatment either alone or in addition to psychological counseling.

Table 3 displays baseline and follow-up PHQ-9 scores. The mean initial PHQ-9 was 14.7, and 32 of 60 patients scored 15 or higher, corresponding to moderately severe and severe symptoms, respectively. For the moderately severe and severe groups, 14 each (88\%) showed an initial response, defined as a drop in score of more than 5 points, at 4 weeks. The mean 8-week PHQ-9 was 5.5, with $72 \%$ showing a $50 \%$ greater drop in score and $63 \%$ scoring less than 5 . Among 18 patients who originally scored 10 to 14 on the PHQ-9, corresponding to moderate symptoms, the 8 -week mean was 5.3 , $67 \%$ scored less than 5 , and $72 \%$ had a $50 \%$ drop. The 8-week PHQ-9 scores ranged from 0 to 20. Five patients did not have a decrease in depression symptoms at 8 weeks. Of these nonresponders, 4 of 5 had indicated at baseline that they had suffered from their symptoms for longer than 2 years.

Table 4 describes telephone activities of the care manager. Most patients received the planned 3 telephone calls during the 8 weeks, but a number received 1 or 2 additional calls and 1 patient received 6 telephone calls. Preferred times to be called ranged throughout the day, and several attempts by the care manager were sometimes 
Table 3. Baseline and Follow-up PHQ-9 Depression Severity Scores ( $\mathrm{n}=60$ patients).

\begin{tabular}{|c|c|c|c|c|c|}
\hline Baseline PHQ-9 Score & No. & $\begin{array}{l}\text { Mean Score } \\
\text { at } 8 \text { Weeks }\end{array}$ & $\begin{array}{c}\geq 5 \text { Point Drop } \\
\text { at } 4 \text { Weeks } \\
\text { No. }(\%)\end{array}$ & $\begin{array}{c}\text { Score }<5 \text { at } \\
8 \text { Weeks } \\
\text { No. }(\%)\end{array}$ & $\begin{array}{c}\text { Decrease of } \geq 50 \% \\
\text { from Baseline } \\
\text { No. }(\%)\end{array}$ \\
\hline Severe major depression, $\geq 20$ & 16 & 6.8 & $14(88)$ & $10(63)$ & $13(82)$ \\
\hline $\begin{array}{l}\text { Moderately severe major } \\
\text { depression, 15-19 }\end{array}$ & 16 & 6.8 & $14(88)$ & $10(63)$ & $10(63)$ \\
\hline $\begin{array}{l}\text { Moderate depression } \\
\text { symptoms, } 10-14\end{array}$ & 18 & 5.3 & $14(78)$ & $12(67)$ & $13(72)$ \\
\hline $\begin{array}{l}\text { Mild or minimal depression } \\
\text { symptoms, }<10\end{array}$ & 10 & 2.6 & $5(50)$ & $9(90)$ & $9(100)$ \\
\hline
\end{tabular}

needed to complete each call. Telephone calls most frequently required 6 to 10 minutes, but calls outside the standard 1-week, 4-week, and 8-week framework required less time on average. These additional telephone calls typically were to follow up on a specific patient need, such as confirming that the patient had filled his or her initial prescription or obtained an appointment for psychological counseling.

Care management supervision calls occurred weekly and required no more than 1 hour each week. The duration of management supervision telephone calls depends on the number of patients being cared for and their compliance, requiring from less than 1 minute of discussion for some initial calls for individual patients who are adhering to the management plan and have no questions, to no more than 5 to 10 minutes for the most complex patients during follow-up calls including telephone administration of PHQ-9. Clinicians called the project psychiatrist for informal advice four times in the duration of the project regarding 4 of the 60 patients $(6.7 \%)$.

Table 5 lists barriers that patients reported to the care manager in adhering to the initial manage-

Table 4. Care Manager Contact $(\mathrm{n}=60$ Patients).

\begin{tabular}{lr}
\hline Characteristics & Percent \\
\hline \multicolumn{2}{l}{ Attempts needed to make first contact } \\
$\quad 1$ & \\
2 & 54 \\
3 & 18 \\
$\geq 4$ & 7 \\
Patients' preferred time & 12 \\
$7-10$ AM & \\
$11-2$ PM & 41 \\
$5-9$ PM & 21 \\
Number of completed calls required & 39 \\
3 & \\
4 & 54 \\
5 & 31 \\
$\geq 6$ & 13 \\
\end{tabular}

ment plan established with their clinician. Thirty of the 60 patients experienced one or more barriers. Most common were medication side effects and ambivalence about taking medication. Most of these barriers were subsequently overcome.

Costs of implementing and of maintaining the program require separate discussion. The most substantial costs concerned initial start-up. Clinicians devoted 2 hours and office staff devoted 30 minutes to initial education meetings as described in the Methods. Care manager training is another start-up expense. Depending on the designated person's training and experience, training could take as little as a few hours to review materials and become familiar with PHQ- 9 to as much as 8 hours for someone with no previous telephone support experience. In this pilot study, using an experienced centrally based person, training required about 2 hours.

Ongoing resource needs include several items. Care manager telephone calls averaged less than 30 minutes per patient during the 2 months. Additional clinician time is needed during the index

Table 5. Initial Barriers to Care Reported by Patients $(\mathrm{n}=30) . *$

\begin{tabular}{lcc}
\hline Barriers to Care & No. (\%) & $\begin{array}{c}\text { Subsequently } \\
\text { Resolved } \\
\text { No. (\%) }\end{array}$ \\
\hline Ambivalence about medication & $7(23)$ & $6(86)$ \\
Medication side effects & $15(50)$ & $13(87)$ \\
Ambivalence about psychological & $2(7)$ & $1(50)$ \\
$\quad$ counseling & $2(6)$ & $2(100)$ \\
$\begin{array}{l}\text { Scheduling counseling } \\
\text { Psychological stressors }\end{array}$ & $2(10)$ & $3(67)$ \\
Insurance issues & $3(10)$ & $3(100)$ \\
Perceived treatment ineffective & $3(10)$ & $3(100)$ \\
\hline
\end{tabular}

* Of the 30 patients who reported barriers, 4 reported more than 1 barrier. 
office visit to have the patient complete the initial PHQ-9 (less than 1 minute), for the clinician to score it (30 seconds), and then to offer patients telephone care manager support and, if the patient agrees, complete a referral form (perhaps another minute). Follow-up office visits require no further clinician time. Anecdotal reports suggest that the care management process saves time in subsequent office visits because the patient is better engaged with care and the clinician has a recent PHQ-9 severity score in hand. Care manager supervision telephone calls involve both care manager and psychiatrist supervisor time and vary widely depending on specific patient needs. During the 2-month period of this project, total supervision discussion time for telephone calls to individual patients ranged from about 5 minutes to as much as 20 minutes.

At the conclusion of the demonstration, clinicians were asked whether they would maintain the office system using internal resources. All but 1 clinician planned to continue to use the PHQ-9 and the routines recommended by AHCPR. Two practices requested training for their own staff to be able to assume the care management function, whereas two practices planned to work with their local hospital quality improvement and social work departments to have this service provided for hospital staff and the community. The fifth (and smallest) practice dropped care management because they believed they could not afford to support it.

\section{Discussion}

The clinicians in this study were able to apply and maintain the depression management office system. Most patients improved. Among those with severe or moderately severe symptoms initially, the symptom score dropped by one half or more at 8 weeks for a substantial majority. The time required of participating practices was 2 hours for clinicians and 30 minutes for staff for initial training, followed by minimal time required to complete communication forms. The primary cost of the project, the $\operatorname{cog}$ that keeps it running, was care manager time including supervision telephone calls.

Most previous studies that provide the evidence basis of depression management have required extensive resources to support improved care for depression. Resources include time and commitment from primary care clinicians as well as expertise and time from project staff. In this demonstration project, the clinician time commitment was modest, and clinicians received continuing medical education credit. Regarding external resources, clinician education and office staff in-services each required a leader. After materials were developed and staff was trained, care manager telephone calls typically required less than 30 minutes total telephone time per patient for the series of calls during the 2 months. The weekly care management supervisory telephone calls required time from a psychiatrist or other clinician. This level of external support for practices is provided now by quality improvement infrastructures of some larger medical groups and insurers, but it could be provided through academic community practice networks or specialty societies, as well through redirecting some of their continuing medical education activities.

What are the implications of this pilot for practicing clinicians? The value of telephone care management is well established for depression. ${ }^{19}$ The PHQ-9 is widely available. Scoring instructions used in this project are available at the Web site: http://www.depression-primarycare.org. The importance of close follow-up of patients, including careful monitoring of their response to treatment with modification of the plan, if needed, is also strongly supported. ${ }^{1,2}$ Recent publication of the ARTIST trial provides further support that close monitoring and, if needed, modification of management results in improved patient outcomes. ${ }^{22}$ In that study, high rates of remission were attained by depressed patients under the care primary care clinicians, but more than one half required a medication change. Telephone care management and close monitoring of patient response can be implemented now for depression using strategies and materials described here. Interested clinicians with the capacity to implement this office system can and should do so now.

It should be noted that the office system makes no mention of screening for depression. This omission is not an oversight. Until evidence-based depression management is available and provided for the more severe patients whom clinicians currently recognize, increasing these numbers with less symptomatic patients (many of whom may represent subthreshold depression or false positives) would result in an overall deterioration in care. For practices that already provide high levels of evidence-based depression care with the capacity to 
care for more patients, screening might be appropriate for some high-risk groups.

Limitations of this pilot project are obvious but important to note. The sample size was small. Participating practices were from one region. No control practices or patients were included. Care managers, who were central to the intervention and thus had an interest in seeing improved severity scores, completed follow-up outcome evaluation using the PHQ-9. Evaluation covered only the short term. We do not know whether these improvements have occurred without the office system, but randomized controlled trials have observed similar levels of improvement with interventions compared with controls. ${ }^{7-11}$

Strengths should be noted as well. Participating practices were independent community practices, and cooperation with the project was excellent. Few patients dropped out, and most of the few who failed to improve had already suffered from a depressive disorder for more than 2 years. Elements of the intervention all have been shown to lead to improved patient outcomes in more resourceintensive, controlled projects. This demonstration project extends that work using transferable, readily available approaches and should be viewed in the context of that previous research to allow application of evidence-based care in community practice.

This project sets the stage for a rigorous effectiveness trial in more representative practices to assess the benefits of the model and the resources required for implementation. Ultimately, insurers will need to provide specific reimbursement for care manager telephone calls and for psychiatrists to supervise care managers and provide telephone consultation to primary care clinicians for truly widespread application of this office system. In the meantime, individual practices, medical groups, and other organizations that desire to implement evidence-based depression management and have the needed resources can use materials available to act now.

Our thanks to Susanna Reed for preparation of this manuscript and to all the clinicians in the local practices who participated in the study.

\section{References}

1. Depression in primary care. Volume 1. Detection, diagnosis, and treatment. Rockville, Md: US Depart- ment of Health and Human Services, Public Health Service, Agency for Health Care Policy and Research, 1993. [AHCPR publication No. 93-0550.]

2. Depression in primary care. Volume 2. Treatment of major depression. Clinical practice guideline, number 5. Rockville, Md: US Department of Health and Human Services, Public Health Service, Agency for Health Care Policy and Research, 1993. [AHCPR publication No 93-0551.]

3. Williams JW, Rost K, Dietrich AJ, Ciotti MC, Zyzanski SJ, Cornell J. Primary care physicians' approach to depressive disorders. Effects of physician specialty and practice structure. Arch Fam Med 1999;8: 58-67.

4. Gerrity MS, Williams JW, Dietrich AJ, Olson AL. Identifying physicians likely to benefit from depression education: a challenge for health care organizations. Med Care 2001;39:856-66.

5. Katon W, Von Korff M, Lin E, et al. Stepped collaborative care for primary care patients with persistent symptoms of depression: a randomized trial. Arch Gen Psychiatry 1999;56:1109-15.

6. Katon W, Von Korff M, Lin E, et al. Collaborative management to achieve treatment guidelines. Impact on depression in primary care. JAMA 1995;273: 1026-31.

7. Hunkeler EM, Meresman JF, Hargreaves WA, et al. Efficacy of nurse telehealth care and peer support in augmenting treatment of depression in primary care. Arch Fam Med 2000;9:700-8.

8. Simon GE, VonKorff M, Rutter C, Wagner E. Randomised trial of monitoring, feedback, and management of care by telephone to improve treatment of depression in primary care. BMJ 2000;320:550-4.

9. Katzelnick DJ, Simon GE, Pearson SD, et al. Randomized trial of a depression management program in high utilizers of medical care. Arch Fam Med 2000;9:345-51.

10. Wells KB, Sherbourne C, Schoenbaum M, et al. Impact of disseminating quality improvement programs for depression in managed primary care: a randomized controlled trial. JAMA 2000;283: 212-20.

11. Rost K, Nutting P, Smith J, Werner J, Duan N. Improving depression outcomes in community primary care practice: a randomized trial of the quEST intervention. Quality Enhancement by Strategic Teaming. J Gen Intern Med 2001;16:143-9.

12. Spitzer RL, Williams JB, Kroenke K, et al. Utility of a new procedure for diagnosing mental disorders in primary care. The PRIME-MD 1000 study. JAMA 1994;272:1749-56.

13. Kroenke K, Spitzer RL, Williams JB. The PHQ-9: validity of a brief depression severity measure. J Gen Intern Med 2001;16:606-13.

14. Wagner EH, Austin BT, Von Korff M. Organizing care for patients with chronic illness. Milbank Q 1996;74:511-44. 
15. Von Korff M, Goldberg D. Improving outcomes in depression. BMJ 2001;323:948-9.

16. Carney PA, Dietrich AJ, Keller A, Landgraf J, O'Connor GT. Tools, teamwork, and tenacity. An office system for cancer prevention. J Fam Pract 1992;35:388-94.

17. Dietrich AJ, O'Connor GT, Keller A, Carney PA, Levy D, Whaley FS. Cancer: improving early cancer detection and prevention. A community practice randomized trial. BMJ 1992 304:687-91.

18. Bordley WC, Margolis PA, Stuart J, Lannon C, Keyes L. Improving preventive service delivery through office systems. Pediatrics 2001;108:E41.

19. Dietrich AJ. The telephone as a new weapon in the battle against depression. Eff Clin Pract 2000; 3:191-3.

20. Diagnostic and statistical manual of mental disorders: DSM-IV. 4th edition. Washington, DC: American Psychiatric Press, 1994.

21. Riegel B, Carlson B, Kopp Z, LePetri B, Glaser D, Unger A. Effect of a standardized nurse casemanagement telephone intervention on resource use in patients with chronic health failure. Arch Intern Med 2002;162:705-12.

22. Kroenke K, West SL, Swindle R, et al. Similar effectiveness of paroxetine, fluoxetine, and sertraline in primary care: a randomized trial. JAMA 2001;286: 2947-55. 